\title{
The effectiveness of pain management methods used at kakamega county teaching \& refferal hospital, Kenya
}

\begin{abstract}
Effective managing acute postoperative pain is a major challenge for practitioners, given that more than $80 \%$ of patients report pain after surgery, and $75 \%$ report the pain as moderate, severe, or even extreme. The American pain Society states that 'In more than half of cases, patients report not receiving adequate pain management following their procedure', which has raised concerns over the development of chronic pain. The objective of the study was to assess the effectiveness of pain management methods used at Kakamega County Teaching and Referral Hospital, Kenya (KCTRH). The study adopted a descriptive cross-sectional study which was carried out KCTRH. The participants in the study included all adult male and female patients who had undergone major surgical procedure within 24 hours post-operative.at KCTRH. The target population, (N) is 250. Purposive sampling method was used, meaning that only patients available during the data collection period and meets the inclusion criteria were included in the sample. Majority of the patients interviewed were aged between 31-40 years and most of the respondents were females accounting to $67(61 \%)$ of the respondents. All the respondents interviewed were Christians and worked in the informal sector. Most of the respondents $80(73 \%)$ reported that painkillers were given through intra-venous. 64(59\%) of the respondents were given general anesthesia whereas $45(41 \%)$ were given regional block type of anesthesia.
\end{abstract}

Volume II Issue 2 - 2019

Consolata Lusweti, Anne Asik

Lecturer, Masinde Muliro University of science and Technology, Kenya

Correspondence: Consolata Lusweti, Lecturer, Masinde Muliro University of science and Technology, Kenya, Tel 072162817I,Email connielusweti@gmail.com

Received: October 17, 2018 | Published: March 05, 2019

Keywords: pain management, effectiveness, post operation

Findings: Post-operative pain management in the first 24 hours is not effective. It is imperative that post-operative pain is adequately managed to alleviate the patients suffering.

Recommendations: Development of pain assessment tool, sensitizing the nurses on the need of pain assessment, hospitals should make analgesic available for use by the patients, a similar study to be conducted using a larger sample size to improve generalizability.

\section{Introduction}

There are different approaches of acute pain management in postsurgical procedures. In a study by ${ }^{1}$ afferent neural blockade with local anesthetics was found to be the most effective analgesic technique followed by high-dose opioids, epidural opioids and clonidine, patient controlled analgesia (PCA) with opioids, and non-steroidal anti-inflammatory agents. Miller et $\mathrm{al}^{2}{ }^{2}$ reports the advantages of effective postoperative pain management to include patient comfort, satisfaction, earlier mobilization, fewer pulmonary and cardiac complications, a reduced risk of deep vein thrombosis, faster recovery with less likelihood of the development of neuropathic or chronic pain, and reduced cost of care. ${ }^{3}$ Managing acute postoperative pain is a major challenge for practitioners, given that more than $80 \%$ of patients report pain after surgery, and $75 \%$ report the pain as moderate, severe, or even extreme. ${ }^{2}$ The American pain Society (APS) states that 'In more than half of cases, patients report not receiving adequate pain management following their procedure', which has raised concerns over the development of chronic pain as per hypothesis of most scholars. ${ }^{4}$ Effective postoperative pain control is an essential component of the care of the surgical patient. ${ }^{5}$ Inadequate pain control, apart from being inhumane, may result in increased morbidity or mortality. ${ }^{6}$ The failure to provide good postoperative analgesia is multifactorial. World health organization ${ }^{7}$ highlights: Insufficient education, fear of complications associated with analgesic drugs, poor pain assessment, and inadequate staffing as the main bottle necks. ${ }^{8}$

\section{Objective}

To assess the effectiveness of pain management methods used at KCTRH, Kenya.

\section{Theoretical framework}

The World Health Organisation (WHO) concurs that pain remains one of the major reason causing medical consultation worldwide. After numerous recommendations, WHO developed the analgesic ladder as a guideline that physicians could use when developing treatment plans for cancer pain. This therapeutic guideline was adopted and has been in use not only for treatment of cancer pain but also for post-operative management of acute and chronic pain. It guideline categorize patients' pain in term of mild, moderate and severe. The analgesic ladder proposes that treatment of pain should begin with a non-opioid medication. If the pain is not properly controlled, one should then introduce a weak opioid. If the use of this medication is insufficient to treat the pain, one can begin a more powerful opioid. One should never use 2 products belonging to the same category simultaneously. The analgesic ladder also includes the possibility of adding adjuvant treatments for neuropathic pain or for symptoms associated with cancer.

WHO recommends the correct use of analgesics and to make best use of the effectiveness of the prescribed analgesics? Suggestions made by WHO include:- 
1. The use of oral of analgesics whenever possible.

2. Analgesics should be given at regular intervals, in accordance with the patient's level of pain. The dosage of medication should be adjusted until the patient is comfortable.

3. Analgesics should be prescribed according to pain intensity as evaluated by a scale of intensity of pain. The prescription must be given according to the level of the patient's pain and not according to the medical staff's perception of the pain.

4. Dosing of pain medication should be metered to the individual requirement therefore pain medications should never be standardized.

\section{Methodology}

The research design was a cross sectional descriptive crosssectional and desk review. Target population was all adult male and female who had undergone a major surgical procedure at KCTRH and are within 24 hours post-operative.

The sample size was determined using the Fischer's formula:

$$
N=\frac{z^{2} p q}{d^{2}}
$$

$\mathrm{N}$ is the desired sample size.

$\mathrm{z}$ is the value from the standard; for a confidence level of $95 \%$, $\mathrm{Z}=1.96$

$\mathrm{p}$ is estimated proportion of the population with desired characteristics

$\mathrm{q}$ Is the proportion of population lacking the desired characteristics?

$\mathrm{d}$ is the desired margin of error; in this case $\mathrm{d}=0.05$.

Thus,

$\mathrm{N}=1.96^{2}(0.5)(0.5) \div 0.05^{\wedge} 2=385$

For a population of less than 10000; the sample size is adjusted as follows
$\mathrm{Nf}=\frac{n}{1+\frac{n}{N}}$

$$
\begin{aligned}
& =385 / 1+385 / 250 \\
& =385 / 2.54 \\
& =151
\end{aligned}
$$

\section{Sampling method}

Purposeful sampling method was used, meaning that only patients who were available during the data collection period and met the inclusion criteria. Data collection was by use of structured questionnaire and patient records review. Data analysis was by excelled and data presentation was done by frequency distribution table, bar graph, pie chart and histogram. Ethical considerations involved seeking clearance by MMUST IREC and KCTRH Ethical committee. Assumptions made were; all the interviewed patients will tell the truth regarding pain score and residual anesthetics will not impair the patients' orientation when responding to the questionnaire (Figure 1) (Table 1).

Table I Frequency distribution table showing the demographic data

\begin{tabular}{lll} 
Socio-demographic data & Frequency $(\mathbf{n = 1 0 9 )}$ & Percentage (\%) \\
\hline Age I8-30 & 42 & 38.5 \\
$31-40$ & 50 & 45.8 \\
$41-50$ & 17 & 15.5 \\
Gender: male & 42 & 38.5 \\
Female & 67 & 61.5 \\
Religion: Christian & 109 & 100 \\
Muslim & 0 & 0 \\
Others & 0 & 0 \\
Occupation: Formal & 7 & 6.4 \\
Informal & 59 & 54.1 \\
Unemployed & 43 & 39.4
\end{tabular}

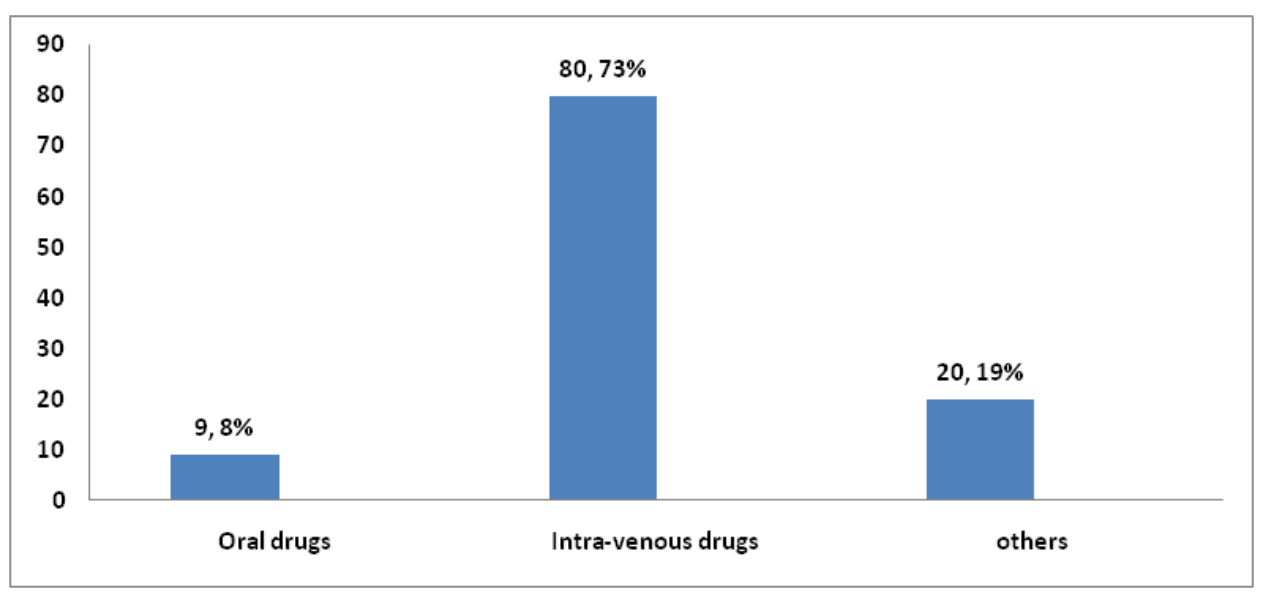

Figure I Distribution of respondents by route of painkillers given in the past $24 \mathrm{hrs}$. 


\section{Data analysis and results}

Majority of the patients interviewed were aged between 31-40 years. Of the 109 respondents, 42(38\%) were aged between 18-30 years, 50(46\%) were aged between $31-40$ years and $17(16 \%)$ were aged between 41-50 years. Most of the respondents were females accounting to $67(61 \%)$ of the respondents whereas $42(39 \%)$ male. All the respondents interviewed were Christians majority of them which makes 59(54\%) of the respondents worked in the informal sector, followed by $43(40 \%)$ who were unemployed and only a small number of $7(6 \%)$ were formally employed (Figure 2). Most of the respondents $80(73 \%)$ reported that painkillers were given through intra-venous, followed by $20(19 \%)$ who reported to be given through other means while a small number of $9(8 \%)$ reported to be given orally (Figure 3 ). $64(59 \%)$ of the respondents were given general anesthesia whereas $45(41 \%)$ were given regional block type of anesthesia.

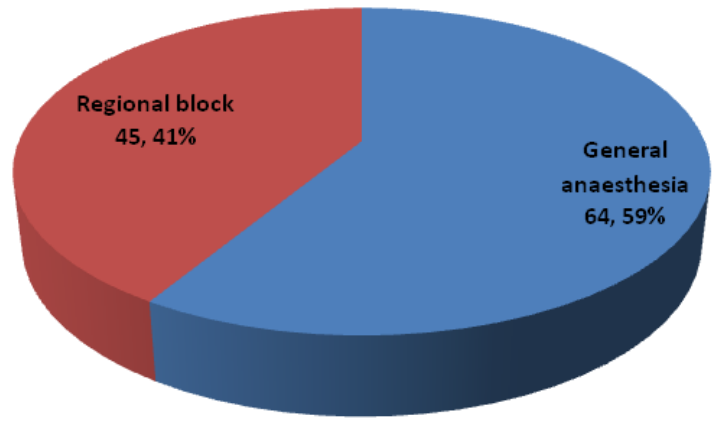

Figure $2 \mathrm{~A}$ pie chart showing the type of anesthesia be given.

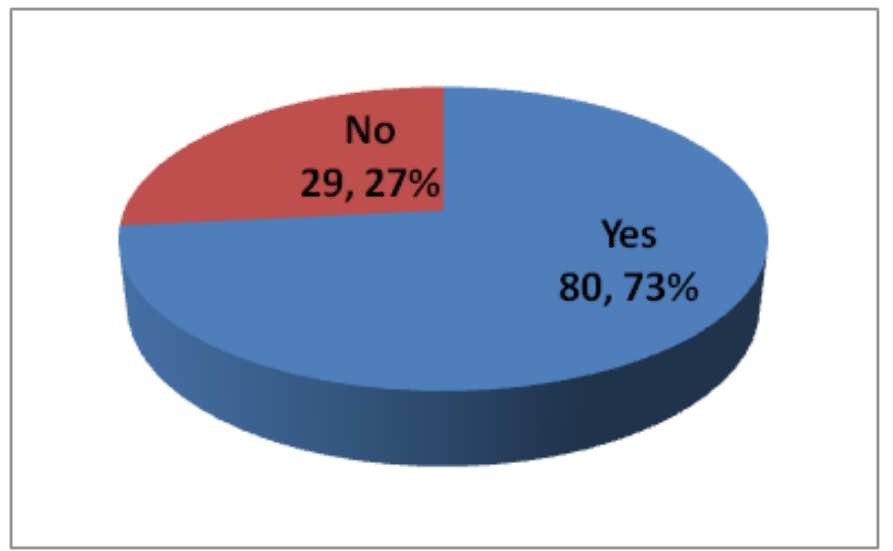

Figure 3 Distribution of respondents by if pain was felt in the $\mathrm{I}^{\text {st }} 24 \mathrm{hrs}$.

\section{Effectiveness of pain management}

$42(39 \%)$ of the respondents reported that their pain was well managed whereas a large number of $67(61 \%)$ reported that their pain was not well managed in the first 24 hours (Figure 4). A large number of respondents $80(73 \%)$ still reported pain in the first 24 hours whereas

Table 2 A frequency distribution table showing the effectiveness of pain management

\begin{tabular}{lcc}
\hline Item & n & $\%$ \\
\hline My pain was well managed in the first 24 hours & Yes $\quad 42$ & 38.5 \\
& 61.4 \\
\hline
\end{tabular}

Citation: Lusweti C,Asik A.The effectiveness of pain management methods used at kakamega county teaching \& refferal hospital, Kenya.J of Anes \& Cri Open Access. 2019;II(2):37-40. DOI: 10.15406/jaccoa.2019.1I.00408
$29(27 \%)$ reported no more pain (Figure 5). Most of the respondents $68(62 \%)$ reported severe pain in the first 24 hours, 29(27\%) reported moderate pain while $12(11 \%)$ reported mild pain (Figure 6). Most of the respondents $45(41 \%)$ felt pain always, 34(31\%) felt pain sometimes while $30(28 \%)$ did not feel any pain (Figure 7). Most of the respondents $79(72 \%)$ reported that the available nurse did not ask how painful the pain was, $18(17 \%)$ reported that the nurse always asked while $12(11 \%)$ reported that the nurse only asked sometimes (Table 2).

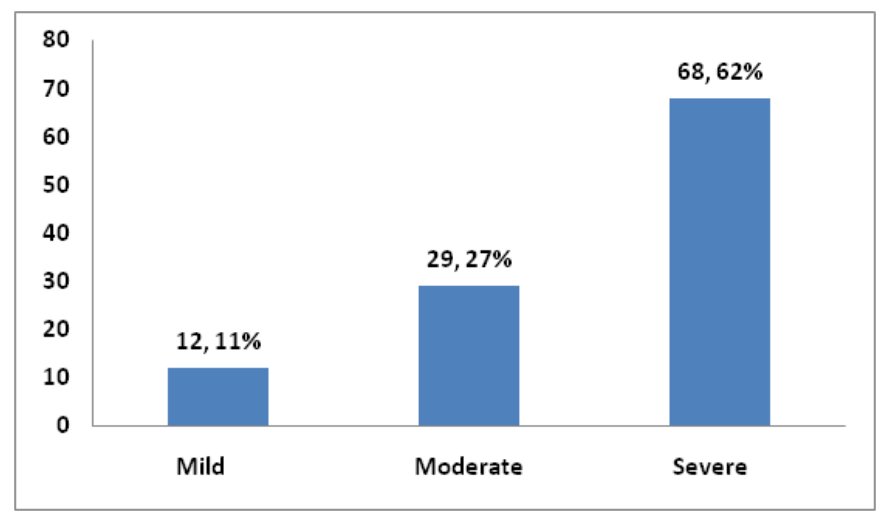

Figure 4 Bar graph showing the nature of pain felt in the Is $24 \mathrm{hrs}$.

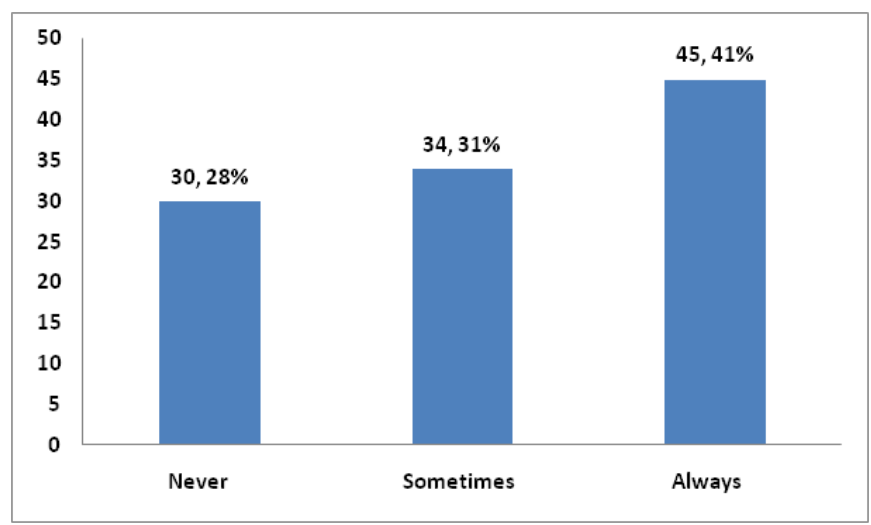

Figure 5 Distribution of Respondents by how often the pain was felt.

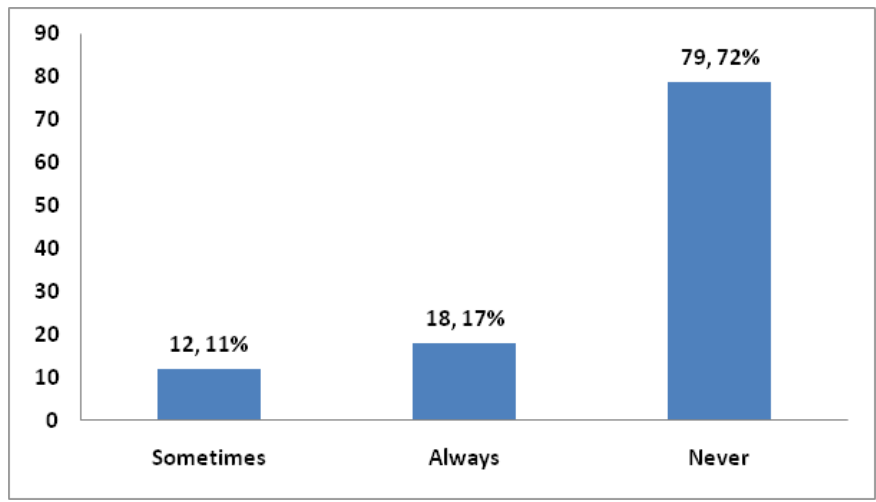

Figure $6 \mathrm{~A}$ bar graph showing pain assessments before administration of painkillers. 
Table Continued....

\begin{tabular}{|c|c|c|}
\hline Item & $\mathbf{n}$ & $\%$ \\
\hline \multirow{2}{*}{ I felt pain in the first 24 hours } & Yes 80 & 73.3 \\
\hline & No 29 & 26.6 \\
\hline \multirow{3}{*}{ The pain I felt in the first 24 hours was } & Mild & II \\
\hline & Moderate 29 & 26.6 \\
\hline & Severe 68 & 62.3 \\
\hline \multirow{3}{*}{ How often were you in severe pain in the first 24 hours? } & Never 30 & 27.5 \\
\hline & Sometimes 34 & $3 I .1$ \\
\hline & Always 45 & 41.2 \\
\hline \multirow{3}{*}{ Did the nurse find out from you how the pain was before giving you painkiller in the first 24 hours } & Sometimes 12 & II \\
\hline & Always & 16.5 \\
\hline & Never & 72.4 \\
\hline
\end{tabular}

\section{Discussion}

Most of the respondents were aged between 31-40 years showing a youthful population in which most of them reported severe to moderate pain in the first 24 hour. The relationship between age and pain perception was not established in this study however other studies have revealed that elderly patients reports less pain and that young ones often rate pain higher than anticipated. Most of the respondents were female, majority had no formal employment. All of our respondents were Christians. Gender, attitude, information status and education are often considered indicators of the patient's perception of power. In our study, less pain intensity was reported by the poor and less educated or informed. This finding affirms the fact that these groups of patients are highly vulnerable and therefore needs greater attention. ${ }^{8}$ Also noted was the fact that the patients who received regional anesthesia reported low pain incidences than those who received general anesthesia. This is due to the fact that regional block prolongs the analgesic effects several hours after operation. The incidence and level of severity of pain reported in this study is higher than those from most Western and developed countries however a similar study done in china reported a $100 \%$ post-operative pain incident. The environment and culture may however explain the variance in the findings of this studies. ${ }^{9}$

Majority of the respondents reported to have received intravenous analgesic in the first 24 hours; this is in line with WHO pain management recommendations. Majority of the patients however believed that the medications administered were not effective with most of them believing that the nurses never assess their pain. Availability of analgesics is also a factor that probably plays a major role in lack of effective pain management. This is because patients are made to buy pain medications and majority are poor and cannot afford effective but expensive drugs. Desk review also revealed lack opioid or stringent control measures that made it difficult for the nurse to administer the prescribed narcotics that are provided by the hospital.

\section{Conclusion and recommendation}

The findings of this study showed that post-operative pain management in the first 24 hours is not effective. It is imperative that post-operative pain is adequately managed to alleviate the patients suffering. In order to achieve this, the study recommends; development of pain assessment tool, sensitizing the nurses on the need of pain assessment, the hospital should make analgesic available for use by the patients and a similar study to be conducted using a larger sample size to improve generalizability.

\section{Acknowledgments}

None.

\section{Conflicts of interest}

Author declares that there is no conflict of interest.

\section{References}

1. Kehlet H. Acute pain control and accelerated postoperative surgical recovery. Surg Clin North Am. 1999;79(2):431-441.

2. Gorno-Tempini ML, Hillis AE, Weintraub S. Classification of primary progressive aphasia and its variants. Neurology. 2011;76(11):1006-1014.

3. Green CR, Anderson KO, Baker TA, et al. The Unequal Burden of Pain: Confronting Racial and Ethnic Disparities in Pain. Pain Med. 2003;4(3):277-294.

4. Boselli J, Solomon DH, Roth CP, et al. The Quality of Medical Care Provided to Vulnerable Older Patients with Chronic Pain. J Am Geriatr Soc. 2004;52(5):756-761.

5. Lautenbacher S, Kunz M, Strate P, et al. Age effects on pain thresholds, temporal summation and spatial summation of heat and pressure pain Pain. 2005;115(3):410-418.

6. Memtsoudis SG, Salvati EA, Go G, et al. Perioperative Pulmonary Circulatory Changes During Bilateral Total Hip Arthroplasty Under Regional Anesthesia. Reg Anesth Pain Med. 2010;35(5):417-421.

7. World Health Organization. Traitement de la douleur cancéreuse. Geneva, Switz: World Health Organization; 2015.

8. Fillingim RB, Edwards RR, Powell T. The relationship of sex and clinical pain to experimental pain responses. Pain. 1999;83(3):419-425.

9. American Society of Anaesthesiologists. Practice Guidelines for Acute Pain Management in the Periopertive Setting. Anesthesiology. 2010;82:4:1071-1081. 